\title{
Impaired delayed but preserved immediate grasping in a neglect patient with parieto-occipital lesions
}

\author{
Stéphanie Rossit ${ }^{\mathrm{a}}$, J. Alexander Fraser ${ }^{\mathrm{b}}$, Robert Teasell ${ }^{\mathrm{c}}$, Paresh A. Malhotra ${ }^{\mathrm{d}}$, Melvyn A. Goodale ${ }^{\mathrm{a}, *}$ \\ a The Centre for Brain and Mind, Department of Psychology, University of Western Ontario, London, Ontario, N6A 5B7, Canada \\ ${ }^{\mathrm{b}}$ Departments of Clinical Neurological Sciences and Ophthalmology, University of Western Ontario, London, Ontario, Canada \\ ${ }^{\mathrm{c}}$ Department of Physical Medicine and Rehabilitation, Lawson Research Institute and Schulich School of Medicine, University of Western Ontario, London, Ontario, Canada \\ ${ }^{\mathrm{d}}$ Centre for Neuroscience, Imperial College London, London, England, UK
}

\section{A R T I C L E I N F O}

\section{Article history:}

Received 17 February 2011

Received in revised form 20 April 2011

Accepted 27 April 2011

Available online xxx

\section{Keywords:}

Perception and action

Dorsal visual stream

Ventral visual stream

Grasping

Parietal-occipital sulcus

Visual neglect

\begin{abstract}
A B S T R A C T
Patients with optic ataxia, a deficit in visually guided action, paradoxically improve when pantomiming an action towards memorized stimuli. Visual form agnosic patient D.F. shows the exact opposite pattern of results: although being able to grasp objects in real-time she loses grip scaling when grasping an object from memory. Here we explored the dissociation between immediate and delayed grasping in a patient (F.S.) who after a parietal-occipital stroke presented with severe left visual neglect, a loss of awareness of the contralesional side of space. Although F.S. had preserved grip scaling even in his neglected field, he was markedly impaired when asked to pretend to grasp a leftward object from memory. Critically, his deficit cannot be simply explained by the absence of continuous on-line visual feedback, as F.S. was also able to grasp leftward objects in real-time when vision was removed. We suggest that regions surrounding the parietal-occipital sulcus, typically damaged in patients with optic ataxia but spared in F.S., seem to be essential for real-time actions. On the other hand, our data indicates that regions in the ventral visual stream, damaged in D.F but intact in F.S., would appear to be necessary but not sufficient for memory-guided action.
\end{abstract}

(c) 2011 Elsevier Ltd. All rights reserved.

\section{Introduction}

Lesions to the posterior parietal cortex are typically associated with optic ataxia (Karnath \& Perenin, 2005; Perenin \& Vighetto, 1988), a disturbance of visually guided hand movements. Several studies have shown that the visuomotor abilities of such patients, in contrast to healthy participants, paradoxically improve when they are asked to pantomime an action towards memorized stimuli (Himmelbach \& Karnath, 2005; Milner et al., 2001; Milner, Dijkerman, McIntosh, Rossetti, \& Pisella, 2003; Rice et al., 2009). In contrast, the visual form agnosic patient, D.F., shows the exact opposite pattern of results: although being able to act in realtime, she loses grip scaling when grasping an object from memory (Goodale, Jakobson, \& Keillor, 1994). Structural MRI showed that D.F. has bilateral lesions primarily affecting ventro-lateral occipital regions (James, Culham, Humphrey, Milner, \& Goodale, 2003). These observations have led to the conclusion that immediate real-time actions rely on processing carried out in the dorsal visual stream (from occipital to posterior parietal cortex) whereas memory-guided actions make use of a perceptual representation of the stimuli generated by the ventral visual stream (from occipital to

\footnotetext{
* Corresponding author. Tel.: +1 519661 2070; fax: +1 5196613961.

E-mail address: mgoodale@uwo.ca (M.A. Goodale).
}

inferior temporal cortex; [Goodale et al., 1994; Goodale, Westwood, \& Milner, 2004; Milner \& Goodale, 2006]).

In addition to optic ataxia, visual neglect is frequently observed after lesions in the parietal lobe (Mort et al., 2003). Patients with neglect typically present with loss of awareness in the contralesional side of space and their lesions most frequently overlap in the inferior parietal lobe (Mort et al., 2003) and/or superior temporal gyrus (Karnath, Berger, Küker, \& Rorden, 2004). Although it has been suggested that such patients exhibit visuomotor deficits (Coulthard, Parton, \& Husain, 2006) the impact of neglect on action tasks has been a hotly debated topic in the last decade (Coulthard Parton, \& Husain, 2007; Himmelbach, Karnath, \& Perenin, 2007). Very briefly, while some authors argue that lesions in the inferior parietal role lead to motor impairments in neglect patients (Mattingley, Husain, Rorden, Kennard, \& Driver, 1998), others argue that even severe neglect patients in the acute stage of their stroke can accurately reach to a target presented in their neglected field (e.g., Himmelbach \& Karnath, 2003). Moreover it has been recently shown that although neglect patients are able to reach towards targets even when these are presented in their neglected field, they are impaired in memory-guided reaching towards these same targets (Rossit et al., 2009a), similar to what has been observed in patient D.F. (Milner, Dijkerman, \& Carey, 1999). This observation is in line with the proposal that the representational system that is damaged in neglect is probably more closely linked to the ven- 
tral stream of processing than to the dorsal (Milner, 1995). In fact since the lesions of the neglect patients included in that study overlapped in the superior temporal gyrus (Rossit et al., 2009a, 2009b, 2009c), it is perhaps not surprising that their immediate reaching performance was unaffected as parietal regions were largely spared.

Therefore, what remains to be clarified is whether, even after lesions in the parietal lobe, neglect patients can accurately perform immediate actions. In addition, the observation that left neglect patients are impaired in delayed (but not immediate) reaching towards left targets raises the question as to whether an analogous deficit would also be observed in grasping tasks, similar to what has been found in patient D.F. (Goodale et al., 1994). To address these issues we explored the dissociation between immediate and delayed grasping in a patient (F.S.) who after a parietal-occipital stroke presented with severe left visual neglect.

\section{Materials and methods}

\subsection{Participants}

Patient F.S. is a 66-year-old male who suffered a right middle cerebral artery stroke three months before the current testing. At time of testing, he presented with a significant left-sided hemiparesis on his upper and lower left limbs, he was alert and oriented, and language functions were normal. Neuropsychological assessment revealed the presence of a profound neglect: he failed to cross any letters on the left side of the page (total score =20; left=0; cut-off = 34 [Wilson, Cockburn, \& Halligan, 1987]), was impaired at star cancellation (total score $=45$; left $=21$; cutoff $=51$ [Wilson et al., 1987]), presented a significant rightward bias in line bisection (average error $=43.2 \mathrm{~mm}$; cut-off $=6 \mathrm{~mm}$ [Harvey, Milner, \& Roberts, 1995]), and an extremely marked lateralized inattention deficit on the Balloons (index $=10 \%$; cufoff $=45 \%$ [Edgeworth, Robertson, \& McMillan, 1998]). On examination of his visual fields, he showed a complete left homonymous hemianopia, but it was unclear whether this was due to his profound visual neglect.

F.S.'s lesion was delineated directly into the patient's clinical MRI (carried out one month post-stroke) by two clinical neurologists (J.A.F. and P.M.), who were unaware of the purpose of the experiment, using MRICROn software package (Rorden \& Brett, 2000). This detailed lesion reconstruction (Fig. 1A) revealed that his lesion extends along the right intraparietal sulcus to the transverse occipital sulcus, affecting the angular gyrus, part of the supramarginal gyrus and superior parietal lobe. The precuneus and the parieto-occipital sulcus are spared. Within F.S.'s occipital lobe, the calcarine fissure is intact, but the lesion extends into Brodmann areas 18 (more so) and 19, just touching the fusiform gyrus and abutting the temporal lobe (sparing the superior temporal gyrus). The lateral occipital complex (LOC), bilaterally damaged in patient D.F. (James et al., 2003), is largely spared in our patient.

In addition to patient F.S., 5 neurologically intact male controls were also tested ( mean age $=64.6$, S.D. $=9.2$ ). Ethical approval was granted the local ethics committee and all participants gave their informed consent prior to participation in the study and were reimbursed for their participation and travel costs.

\subsection{Apparatus}

As in previous studies (Goodale et al., 1994; Milner et al., 2001, 2003), we used Efron objects (Efron, 1969) varying in width, but of constant surface area. Four different wooden objects were used of dimensions (width $\times$ height): $5 \mathrm{~cm} \times 5 \mathrm{~cm}$, $4 \mathrm{~cm} \times 6.25 \mathrm{~cm}, 3 \mathrm{~cm} \times 8.3 \mathrm{~cm}$ and $2 \mathrm{~cm} \times 12.5 \mathrm{~cm}$ (all $1 \mathrm{~cm}$ thick; Fig. $1 \mathrm{~b}$ ). They were presented at a depth of $25 \mathrm{~cm}$, either to the left or right $(10 \mathrm{~cm})$, from a start trigger aligned with the participant's midline. The objects were presented in a pseudorandomized order (no object was presented twice in succession) on a 40-inch touch screen (NEC MultiSync ${ }^{\circ}$ LCD4020) lying horizontally, which displayed the position and size of the stimulus to the experimenter before the start of each trial. Participants wore a pair of PLATO goggles (Translucent Technologies) to control for stimulus presentation. In between trials, the goggles remained closed (i.e., in opaque configuration) and headphones played loud white noise to mask any auditory cues from the placement of the objects.

Participants began each trial with the right thumb and index finger touching one another and depressing the start trigger. With the PLATO goggles in the translucent configuration, the experimenter placed one of the four objects on the touch screen surface in one of the two positions (left or right). After a ready signal from the experiment, the goggles changed to transparent configuration allowing the participant to view the object for $5 \mathrm{~s}$ (viewing period). In all tasks, participants grasped the object by its width (Fig. 1b) and were reminded to wait for the auditory cue ( $50 \mathrm{~ms}$ ) before responding. Due to the potential presence of concomitant hemianopia in the patient, eye movements were unrestricted for all tasks.

In experiment 1, which was based on previous experiments (Goodale et al., 1994; Milner et al., 2001, 2003), we asked participants to perform two delayed grasping tasks towards objects located either on the left or right sides of space: delayed real (in which the object reappeared after a 2-s delay) and delayed pantomime (in which the object was absent after the delay; see Fig. 1b). In the delayed pantomime condition, participants were required to refrain from grasping the object for a delay period of $2 \mathrm{~s}$, during which the object was removed, and then to pretend to grasp it as if it was physically present. In the delayed real grasping task the procedure was similar except that at the end of the delay the object could now be seen and it remained present during the entire movement, allowing on-line visual guidance.

In experiment 2 we compared F.S.'s grip scaling with that of controls during immediate grasping conditions in which visual feedback was manipulated. The objective of this experiment was to rule out the explanation that any impairment observed in the delayed pantomime condition was due to the absence of on-line visual feedback; after all, the object was not present during the execution of the grasp. In the closed-loop version of this task, the workspace was continuously viewed, but in open loop, this visual feedback was removed. Critically, vision was removed only at movement onset, allowing F.S. and the controls to program their grasps on the basis of a visible object not on a memory of what they had seen earlier (Westwood \& Goodale, 2003).

Six grasps were made for each of the 8 possible combinations of object sizes (4) $\times$ positions (2), for a total of 48 trials (plus 5 practise trials) per condition. A custom Matlab program (version 6.5) was used to control stimulus presentation, headphones, goggles and data recording. Movements were recorded (at $200 \mathrm{~Hz}$ ) for $3 \mathrm{~s}$ using three infrared emitting diodes taped to the surface of the right hand (one on the tip of the index finger, one on the tip of the thumb and one on the wrist; see Fig. 1B) via an OPTOTRACK motion tracking system (Northern Digital Inc., Waterloo, Canada).

\subsection{Analysis}

A custom-designed analysis program written with Labview (National Instruments, Newbury, UK) was used to calculate the maximum grip aperture (MGA; i.e., the distance between his finger and thumb in $\mathrm{mm}$ ). A linear regression analysis was performed to obtain the $r^{2}$ values between object width and MGA separately for each condition (delayed real, delayed pantomime, immediate closed and open loop) and position (left and right). In addition, $r^{2}$ values for grip scaling for each condition and side were converted to a Fisher transformed $r$. The mean MGAs were also computed for each object and side. The patient's performance was compared to that of the controls using two-tailed single-case statistics (Crawford \& Garthwaite, 2002). Furthermore, to test whether F.S.'s grasping showed a significant dissociation between the left and right sides of space (i.e., compared to the corresponding differences in the control sample), we applied the Revised Standardized Difference Test (Crawford \& Garthwaite, 2005) on the Fisher transformed $r$.

\section{Results}

\subsection{Experiment 1: delayed grasping}

As can been seen in Fig. 2a, during delayed real grasping patient F.S. scaled his grip aperture to the object sizes presented on both the left and right sides of space (left: $r^{2}=0.66 ; F[1,24]=33.2, p<0.0001$; right: $\left.r^{2}=0.73 ; F[1,24]=45.88, p<0.0001\right)$. In fact, when compared to the controls, F.S.'s grip scaling was in the normal range for objects presented on both sides of space (Fig. 2b). Moreover his maximum grip aperture (MGA) was also within the normal range for all object sizes and positions, indicating that he opened his hand in a similar way to controls. Thus, despite his severe left visual neglect, F.S. was able to tailor his grip to the size of a visible object even when it was presented in his neglected field.

When F.S. made delayed pantomime grasps, he showed quite a different pattern of performance. Even though F.S. was able to scale his grip to the size of objects presented on the right side of space $\left(r^{2}=0.81 ; F[1,24]=70.40, p<0.0001\right)$, he showed only weak evidence of grip scaling for objects presented on the left $\left(r^{2}=0.25\right.$; $F[1,24]=6.85, p<0.05$; Fig. 3a). In fact, for objects on the left, the relationship between grip aperture and the width of those objects was much weaker in F.S. than it was in the healthy participants $(t=-4.82, p<0.01$; Fig. $3 \mathrm{~b})$. This was not true for objects on the right where F.S. showed normal scaling. It seems that F.S. adopted a conservative strategy of opening his hand wide regardless of the size of the object - and in fact his MGA for the smallest object $(20 \mathrm{~mm})$ was significantly larger than it was in the controls, but again only for objects on the left side of space (mean F.S. $=93.6 \mathrm{~mm}$; mean controls $=50.2$, S.D. $=13.3 ; t=4.32, p=0.01)$. F.S.'s behavior contrasts to 
(a)
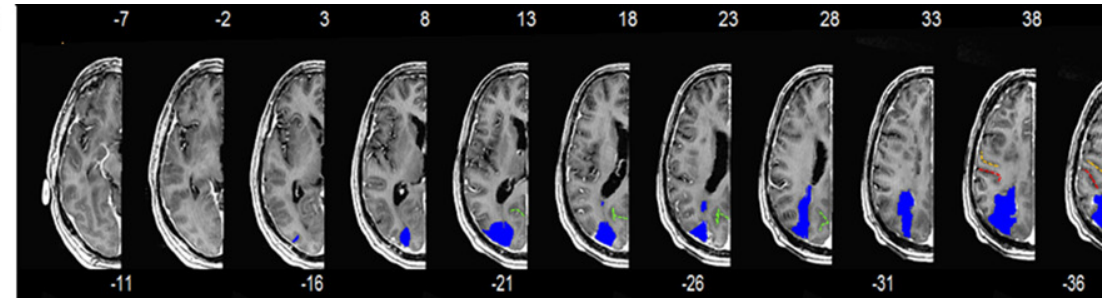

43
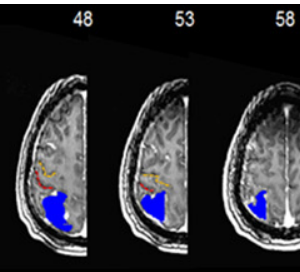

31

36
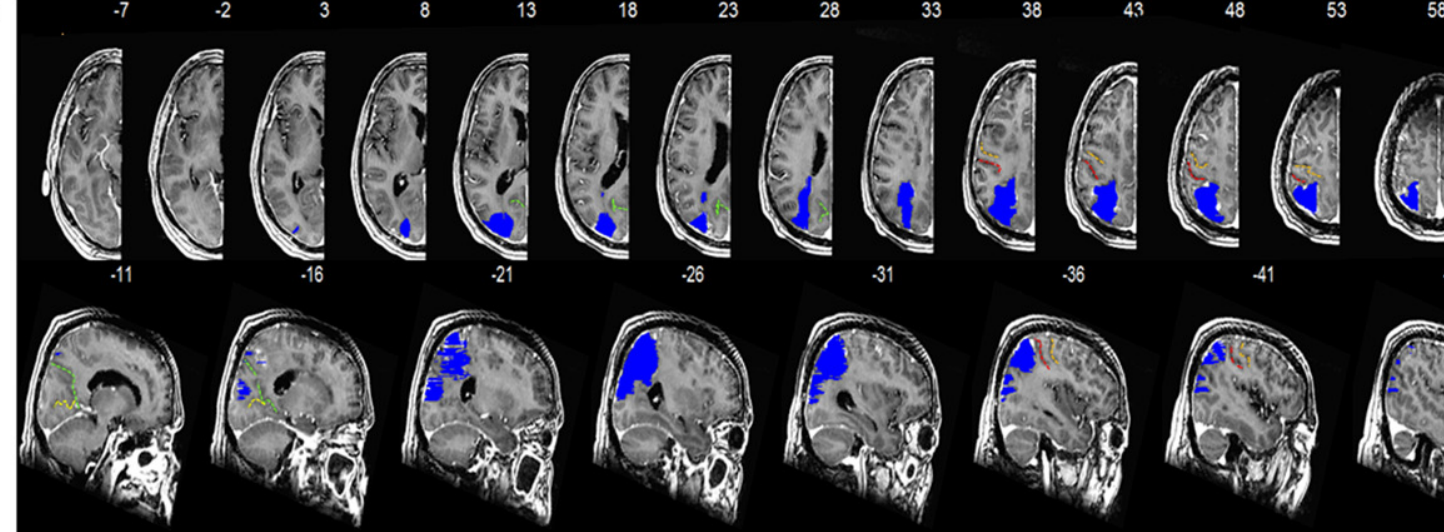

$-41$

$-46$

.96

$-91 \quad-86$

$-81$

$-76$

$-71$

$\begin{array}{ll}-66 & -61\end{array}$

$-56$
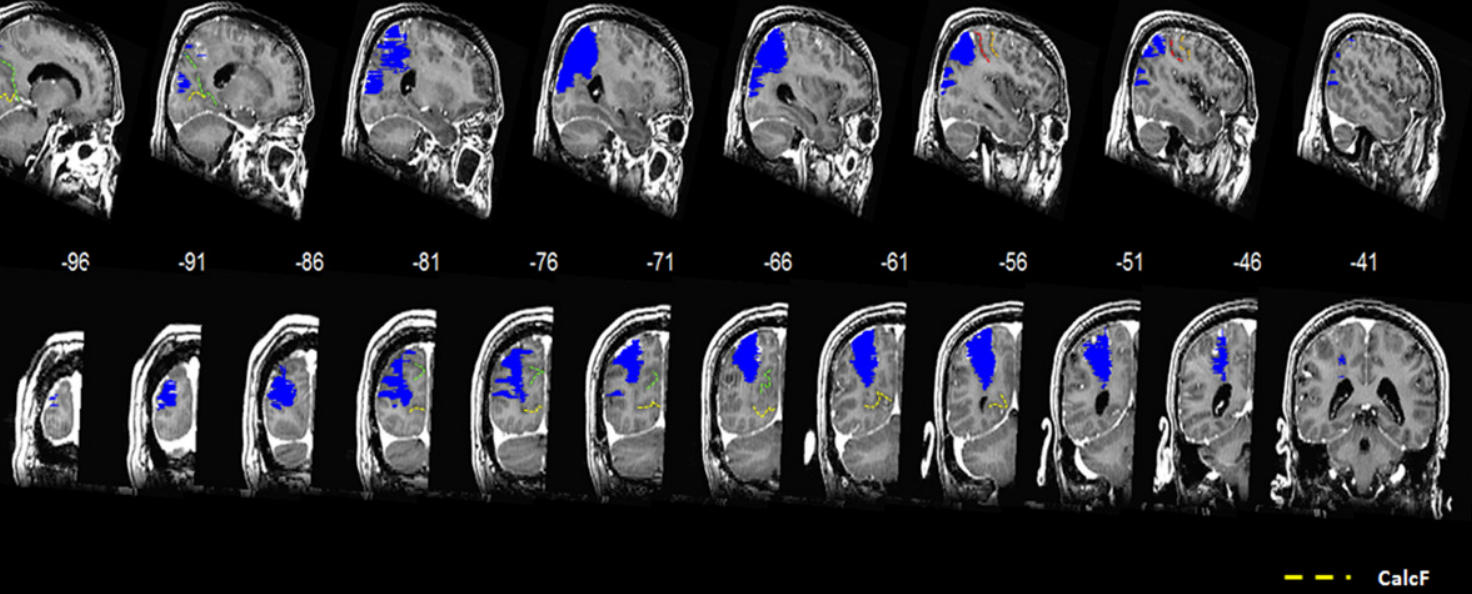

- - POS

- PostCS

- - cs

lesion

(b)

Delayed real grasping

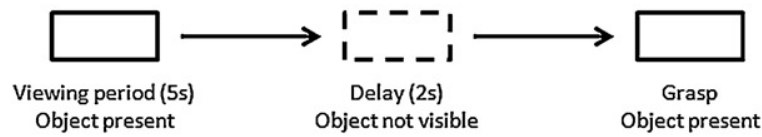

Delayed pantomime grasping
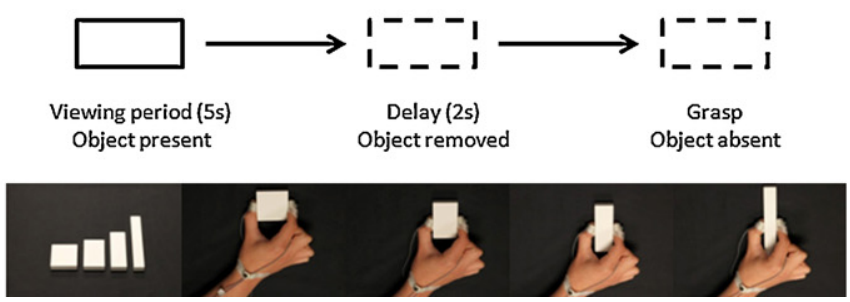

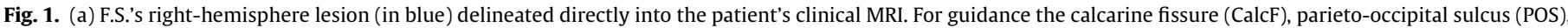
post-central sulcus (PostCS) and central suclus (CS) are delineated. (b) Schematic of the two delayed grasping conditions and Efron objects used.

that of the healthy participants who open their hand less widely in pantomiming than in real grasping conditions (Goodale et al., 1994).

Further analysis revealed a significant dissociation between delayed real grasping and delayed pantomime in F.S. when compared to controls $(t=4.51, p=0.01)$ : although he was able to scale his grip on-line (delayed real) in a similar way for objects on both the left and right sides of space, he was considerably impaired when he had to rely on visual memory (delayed pantomime) for leftward (but not rightward) grasps. Of course, F.S.'s impairment cannot be simply explained by appealing to some sort of non-specific deficit due to brain damage because it shows a clear double dissociation from the impairment shown by the optic ataxic patient I.G., tested by Milner et al. (2001). In stark contrast to F.S., I.G. showed very poor grip scaling in delayed real grasping, but relatively intact grip scaling in delayed pantomime grasping (Fig. 3c).

\subsection{Experiment 2: closed vs. open-loop immediate grasping}

It could be the case that F.S.'s impairment in the delayed pantomime condition was due to the absence of on-line visual feedback; after all, the object was not present during the execution of the grasp. To rule out this explanation, we further compared F.S.'s grip scaling with that of controls in closed- and open-loop immediate grasping conditions. F.S. was able to scale his grasp for objects presented on the right and left sides of space not only in the closed-loop condition (left: $r^{2}=0.86 ; F[1,24]=119.56, p<0.0001$; right: $r^{2}=0.91 ; F[1,24]=172.01, p<0.0001 ;$ Fig. 4a) but also in open loop when no feedback was available (left: $r^{2}=0.75 ; F[1,24]=42.54$, $p<0.0001$; right: $r^{2}=0.83 ; F[1,24]=68.15, p<0.0001$; Fig. $\left.4 b\right)$. In line with this, his grip scaling was also within the normal range for all conditions and both sides of space. Moreover, his MGA for all object sizes and positions in either open- or closed-loop condi- 

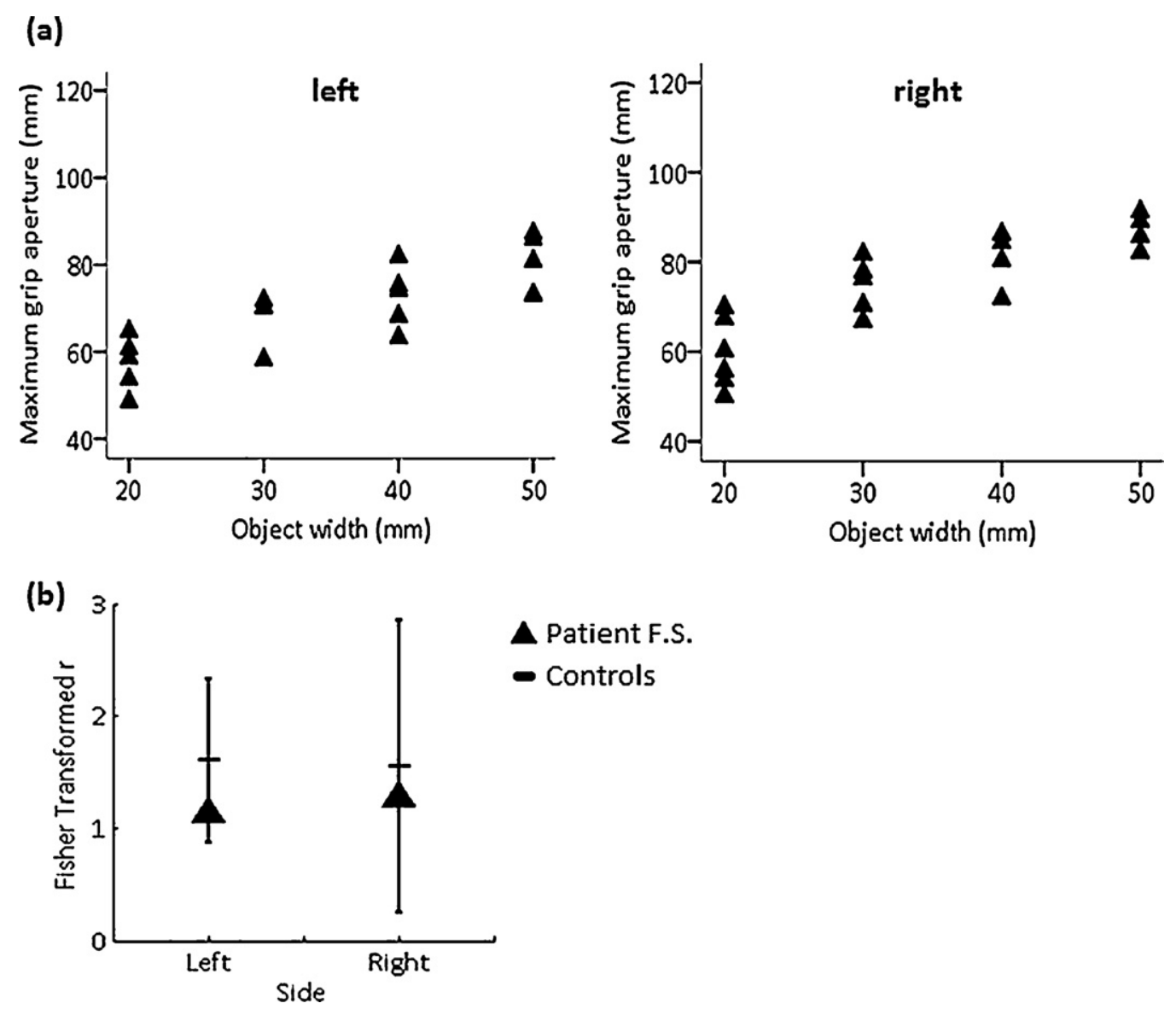

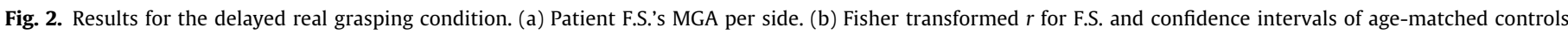
obtained with single-case statistics per side (Crawford \& Garthwaite, 2002).

tions was completely normal (Fig. 4c). Of course, the finding that F.S.'s grip scaling is normal in the immediate closed-loop condition is not surprising given that his grip scaling was also spared in delayed real grasping where he could also see the object during the grasp. However, the fact that he was also able to scale his grip in the open-loop condition indicates that the impairment we found in leftward delayed pantomime grasping reflects a deficit in his ability to use information about objects that were presented earlier in his neglected field.

\section{Discussion}

Patients with optic ataxia, a deficit in visually guided action, paradoxically improve when pantomiming an action towards memorized stimuli (Himmelbach \& Karnath, 2005; Milner et al., 2001, 2003; Rice et al., 2009). Visual form agnosic patient D.F. shows the exact opposite pattern of results: although being able to grasp objects in real-time she loses grip scaling when grasping an object from memory (Goodale et al., 1994, 2004). Here we explored the dissociation between immediate and delayed grasping in a patient (F.S.) who after a parietal-occipital stroke presented with severe left visual neglect.

In experiment 1 , we established that F.S. was perfectly capable of grasping visible objects, even when these were presented in his neglected field. On the other hand, when asked to pretend to grasp an object seen earlier, but no longer present, he lost the ability to grip scale to objects on the left but not the right side of space. Of course this dissociation could simply result from the fact that in the delayed pantomime condition, on-line visual information about the object was unavailable during the execution of the movement. This hypothesis was refuted in experiment 2, however, where we failed to find any differences between F.S. and controls in both open- and closed-loop real-time grasping directed at objects on both the left and right sides of space, similar to what was has been reported in other studies (Farnè et al., 2003; Harvey et al., 2002; McIntosh, Pritchard, Dijkerman, Milner, \& Roberts, 2002). These findings clearly indicate that F.S.'s deficit in the delayed pantomime task arises because of some failure in his ability to use memory-based information for action, a failure that is remarkable reminiscent of the one described in D.F. (Goodale et al., 1994, 2004). Moreover, our findings suggest that both grasping and reaching towards leftward targets seem to be affected by neglect in delayed but not immediate conditions (Rossit et al., 2009a, 2009b, 2009c).

The fact that F.S. has spared real-time visuomotor abilities, despite a large lesion in his posterior parietal cortex is rather puzzling. Typically, such lesions, particularly when they involve the superior parietal lobe (SPL) and/or intraparietal sulcus, lead to optic ataxia (Perenin \& Vighetto, 1988). Yet these were the very regions damaged in F.S. Recently, however, Karnath and Perenin (2005) have demonstrated that optic ataxia is not associated with SPL damage, but instead with lesions centered in the lateral and medial convexity near the parieto-occipital sulcus. Notably the parietal-occipital sulcus is largely unaffected in F.S. (see Fig. 1a, POS delineation) and is thought to be integral for the on-line transformations of visual information into action coordinates (for review see Milner \& Goodale, 2006). In fact, damage to these regions surrounding the parieto-occipital sulcus not only results in optic ataxia (Karnath \& Perenin, 2005) but also in open-loop reaching deficits in right-hemisphere stroke patients (Rossit et al., 2009b). Taken together, these findings are inconsistent with previous interpre- 
(a)
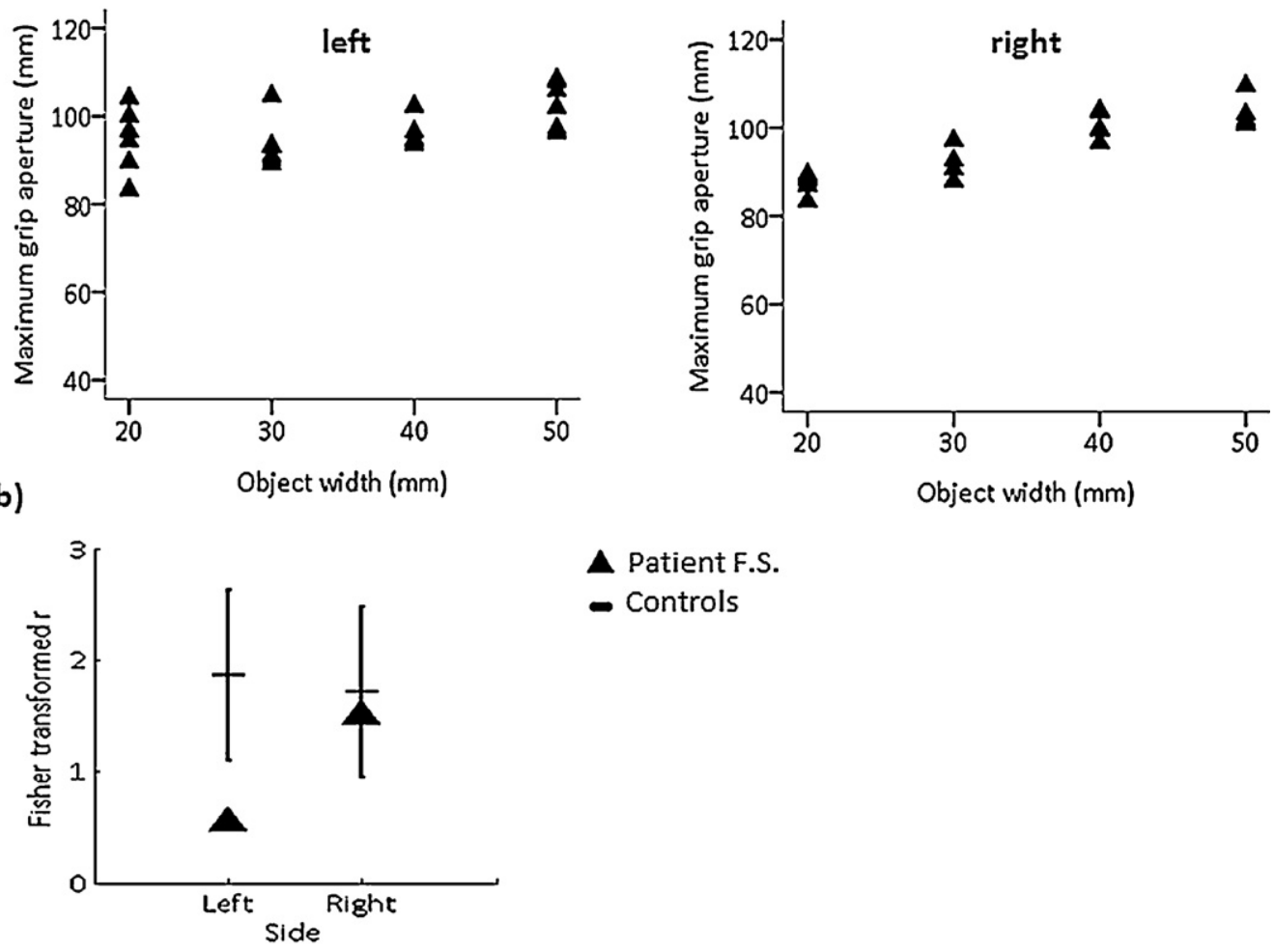

$\Delta$ Patient F.S.

- Controls

(c)

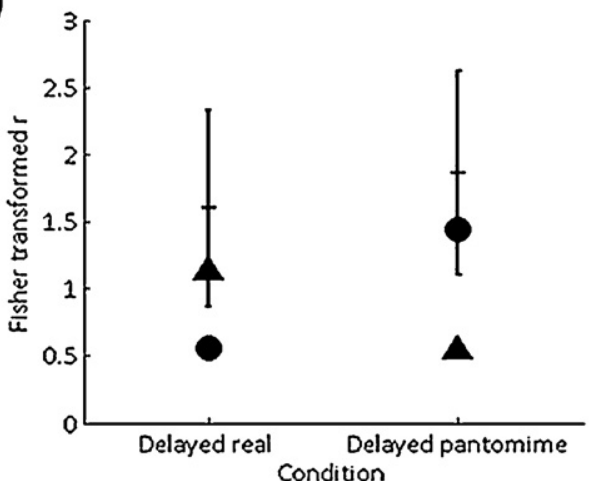

$\Delta$ Patient F.S.

Patient I.G.

- Controls

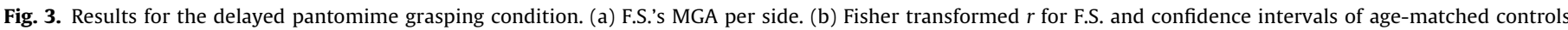

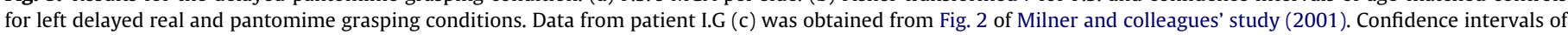
age-matched controls were calculated with single-case statistics (Crawford \& Garthwaite, 2002).

tations that have suggested that spared visuomotor function in neglect patients is mediated by an intact superior parietal lobe (e.g., McIntosh, McClements, Dijkerman, Birchall, \& Milner, 2004; Perenin, 1997) and others that have suggested that lesions in the right inferior parietal lobule are accompanied by motor abnormalities (Coulthard et al., 2006; Mattingley et al., 1998). Even though F.S. has lesions that compromised both the inferior and superior parietal lobules in his right hemisphere, leaving him with a severe left visual neglect, he could still grasp objects accurately in real-time in his neglected field.

Despite the absence of damage to the parieto-occipital sulcus - and the sparing of real-time grasping, F.S. shows a profound deficit in his ability to pantomime movements on the basis of earlier visual information about the target object. This suggests that such regions by themselves cannot mediate memory-guided grasping. Goodale and colleagues (Goodale et al., 1994, 2004; Milner \& Goodale, 2006) argued that such visual memory for object features instead appears to depend on the perceptual mechanisms that reside in the ventral visual stream. However, the lesion in our neglect patient does not extend into the object-related lateral occipital complex (LOC), which is bilaterally damaged in D.F. (James et al., 2003). This suggests that even though this ventral-stream area may play a critical role in the performance of delayed actions (Goodale et al., 1994, 2004; Milner et al., 1999b, 2003; Milner \& Goodale, 2006; Rossetti \& Pisella, 2002), it is not sufficient. Other areas, presumably damaged in F.S., must contribute to the computations underlying the performance of memory-guided actions. In fact, our data are remarkably in line with a very recent fMRI study which found elevated activity throughout the delay period, before grasp execution, in the inferior parietal cortex only in the right hemisphere (Fiehler et al., 2011). It is also interesting to note that another fMRI study has reported that pantomimed actions performed in real-time alongside the target object showed activation in temporo-parietal regions, but again only in the right hemisphere (Króliczak, Cavina-Pratesi, Goodman, \& Culham, 2007). To determine more precisely the contributions of different brain areas to 
(a)

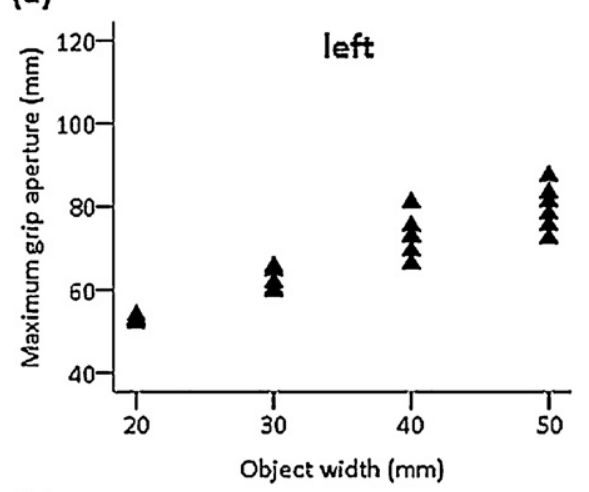

(b)

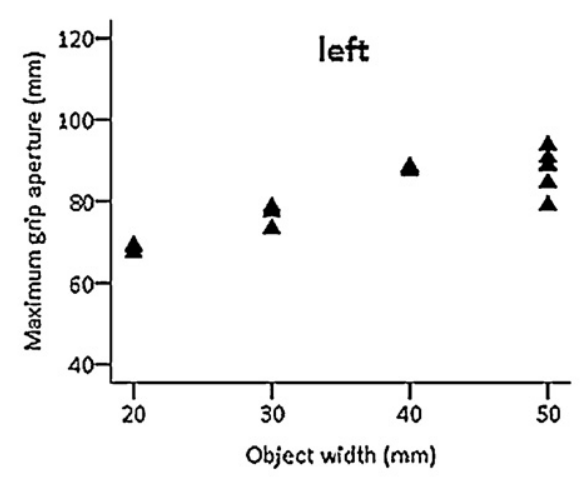

(c)

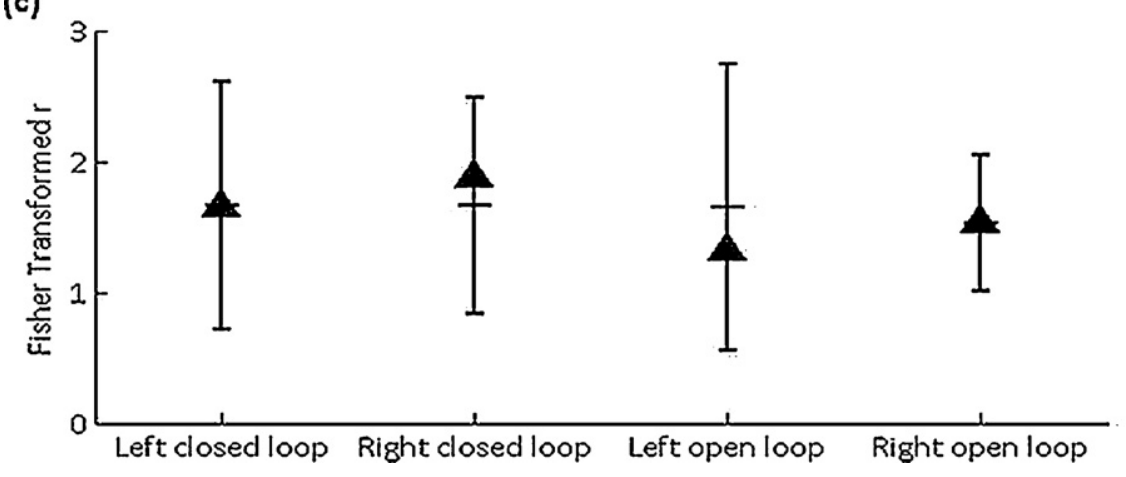

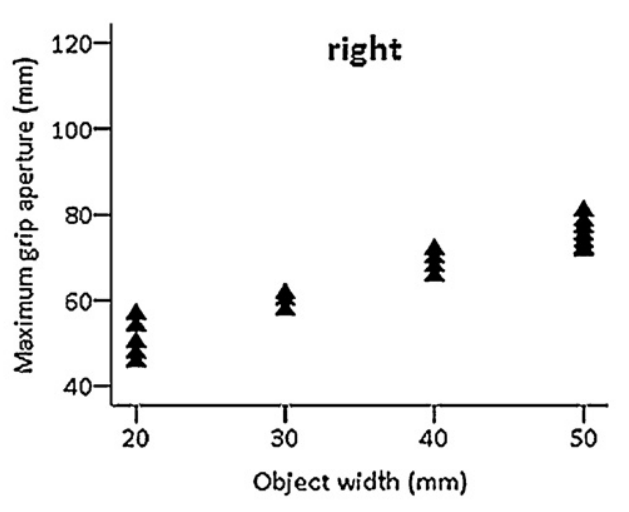

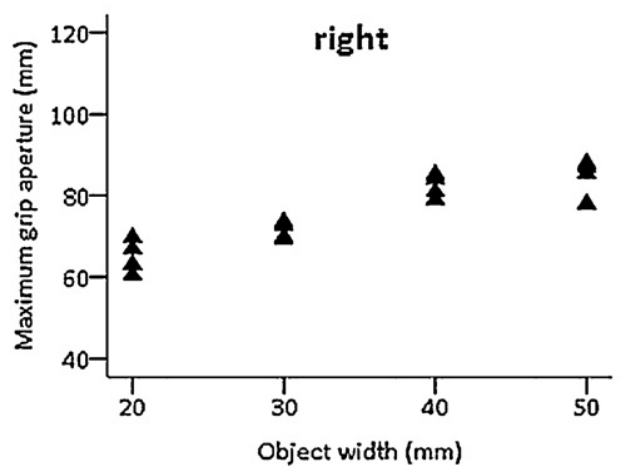

$\Delta$ Patient F.S.

Controls

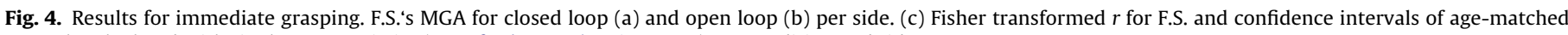
controls calculated with single-case statistics (Crawford \& Garthwaite, 2002) per condition and side.

real-time and delayed grasping, however, will require a systematic lesion-symptom mapping study.

The current findings expand the perception and action model (Goodale et al., 2004; Milner \& Goodale, 2006) as they clearly indicate that the ventral visual stream is not sufficient for off-line actions. In particular, we believe that delayed pantomime grasping depends on a tight interaction between perception and action. In fact, James et al. (2003) reported that, in addition to ventral occipital lesions, D.F. also presents with a small lesion in the left posterior parietal cortex and, unlike in healthy controls, they failed to find activation in her left anterior intraparietal sulcus, a region activated during grasping (Culham, 2004), although she did show such activation in the corresponding area on the right. Although the consequences of this parietal damage remain to be fully explored in D.F., it is quite possible that the deficit in delayed grasping in both F.S. and D.F. results from a disconnection between the ventral and the dorsal visual streams. In other words, the lateral occipital complex (damaged in D.F.; James et al., 2003) in conjunction with temporal-parietal regions (typically damaged in neglect patients, [Karnath, Berger, Kuker, \& Rorden, 2004; Mort et al., 2003]) pro- vides the conscious perceptual representation of objects (Milner, 1995). We would argue, however, that the absence of such conscious representation in both our neglect patient and D.F. deprives not only the memory systems but also the dorsal visual stream of crucial visual information for action on remembered objects. This perspective, while contrasting with the earlier view that the dorsal visual stream is not essential for delayed actions (Goodale et al., 1994; Milner et al., 1999b, 2001, 2003; Rossetti \& Pisella, 2002), fits well with recent findings of dorsal visual stream involvement during both immediate and delayed actions in healthy participants (Cohen, Cross, Tunik, Grafton, \& Culham, 2009; Fiehler et al., 2011; Himmelbach et al., 2009; Singhal, Kaufman, Valyear, \& Culham, 2006) and with the observation that although optic ataxia improves with delay, such patients are still impaired when compared to healthy controls (Himmelbach \& Karnath, 2005). Nevertheless, these patients do show some improvement and, for this reason, the way in which such improvement is achieved deserves further investigation.

The present evidence is in line with the view that not all actions depend exclusively on dorsal visual stream processing 
(Goodale et al., 2004; Milner \& Goodale, 2006). Here we argue, however, that memory-guided actions depend on a tight collaboration between the ventral and dorsal visual streams, rather than on object-related processing regions alone (Goodale et al., 1994; Milner et al., 1999b, 2001, 2003; Rossetti \& Pisella, 2002). In contrast to patients with optic ataxia, who do show some improvement with delay (Himmelbach \& Karnath, 2005; Milner et al., 2001, 2003; Rice et al., 2009), F.S.'s performance was considerably impaired (even though he shows excellent grip scaling in real-time), suggesting that the integration between ventral and dorsal processing is severely disrupted. We propose that this preserved visuomotor function is accomplished by spared regions surrounding the parieto-occipital sulcus in F.S. that by themselves are not sufficient for successful memory-guided grasping.

\section{Acknowledgements}

The authors are grateful to F.S. and the 5 healthy controls for their participation. We would also like to thank Haitao Yang and Gavin Buckingham for their helpful advice at set-up stage and Jody C. Culham for discussions about F.S.'s lesion. S. Rossit was funded by a post-doctoral fellowship from the Portuguese Foundation for Science and Technology and the Social European Fund (grant SFRH/BPD/65951/2009). This research was funded by a grant from the Canadian Institutes of Health Research to Melvyn A. Goodale.

\section{References}

Cohen, N. R., Cross, E. S., Tunik, E., Grafton, S. T., \& Culham, J. C. (2009). Ventral and dorsal stream contributions to immediate and delayed grasping: A TMS approach. Neuropsychologia, 47, 1553-1562.

Coulthard, E., Parton, A., \& Husain, M. (2007). The modular architecture of the neglect syndrome: implications for action control in visual neglect. Neuropsychologia, 45 , 1982-1984.

Coulthard, E., Parton, A., \& Husain, M. (2006). Action control in visual neglect. Neuropsychologia, 44, 2717-2733.

Crawford, J. R., \& Garthwaite, P. H. (2002). Investigation of the single case in neuropsychology: Confidence limits on the abnormality of test scores and test score differences. Neuropsychologia, 40,1196-1208.

Crawford, J. R., \& Garthwaite, P.H. (2005). Testing for suspected impairments and dissociations in single-case studies in neuropsychology: Evaluation of alternatives using Monte Carlo simulations and revised tests for dissociations. Neuropsychology, 19, 318-331.

Culham, J. (2004). Human brain imaging reveals a parietal area specialized for grasping. In N. Kanwisher, \& J. Duncan (Eds.), Functional neuroimaging of visual cognition: Attention and performance XX (pp. 417-438). Oxford: Oxford University Press.

Edgeworth, J. A., Robertson, I. H., \& McMillan, T. M. (1998). The balloons test. Bury St. Edmunds: Thames Valley Test Company Limited.

Efron, R. (1969). What is perception? Boston Studies in the Philosophy of Science, 4, $137-173$.

Farnè, A., Roy, A. C., Paulignan, Y., Rode, G., Rossetti, Y., Boisson, D., \& Jeannerod, M. (2003). Visuo-motor control of the ipsilateral hand: evidence from right-brain damaged patients. Neuropsychologia, 41, 739-757.

Fiehler, K., Bannert, M. M., Bischoff, M., Blecker, C., Stark, R., Vaitl, D., Franz, V. H., \& Rösler, F. (2011). Working memory maintenance of grasp-target information in the human posterior parietal cortex. Neuroimage, 54, 2401-2411.

Goodale, M. A., Jakobson, L. S., \& Keillor, J. M. (1994). Differences in the visual control of pantomimed and natural grasping movements. Neuropsychologia, 10, 1159-1178.

Goodale, M. A., Westwood, D. A., \& Milner, A. D. (2004). Two distinct modes of control for object-directed action. Progress in Brain Research, 144, 131-144.

Harvey, M., Jackson, S. R., Newport, R., Krämer, T., Morris, D. L., \& Dow, L. (2002). Is grasping impaired in hemispatial neglect? Behavioral Neurology, 13, 17-28.

Harvey, M., Milner, A. D., \& Roberts, R. C. (1995). An investigation of hemispatial neglect using the landmark task. Brain and Cognition, 27, 59-78.

Himmelbach, M., \& Karnath, H.-O. (2003). Goal-directed hand movements are not affected by the biased space representation in spatial neglect. Journal of Cognitive Neuroscience, 15, 972-980.

Himmelbach, M., \& Karnath, H.-O. (2005). Dorsal and ventral stream interaction: contributions from optic ataxia. Journal of Cognitive Neuroscience, 17, 632-640.
Himmelbach, M., Karnath, H.-O., \& Perenin, M.-T. (2007). Action control is not affected in hemispatial neglect: a comment on Coulthard et al. Neuropsychologia, 45, 1979-1981.

Himmelbach, M., Nau, M., Zündorf, I., Erb, M., Perenin, M.-T., \& Karnath, H.-O. (2009). Brain activation during immediate and delayed reaching in optic ataxia. Neuropsychologia, 47, 1508-1517.

James, T. W., Culham, J., Humphrey, G. K., Milner, A. D., \& Goodale, M. A. (2003). Ventral occipital lesions impair object recognition but not object-directed grasping: An fMRI study. Brain, 126, 2463-2475.

Karnath, H.-O., \& Perenin, M. T. (2005). Cortical control of visually guided reaching: Evidence from patients with optic ataxia. Cerebral Cortex, 15, 1561-1569.

Karnath, H.-O., Berger, M. F., Küker, W., \& Rorden, C. (2004). The anatomy of spatial neglect based on voxelwise statistical analysis: A study of 140 patients. Cerebral Cortex, 14, 1164-1172.

Króliczak, G., Cavina-Pratesi, C., Goodman, D., \& Culham, J. C. (2007). What does the brain do when you fake it? An fMRI study of pantomimed and real grasping. Journal of Neurophysiology, 97, 2410-2422.

Mattingley, J. B., Husain, M., Rorden, C., Kennard, C., \& Driver, J. (1998). Motor role of the inferior parietal lobe revealed in unilateral neglect patients. Nature, 392, 179-182.

McIntosh, R. D., McClements, K. I., Dijkerman, H. C., Birchall, D., \& Milner, A. D. (2004). Preserved obstacle avoidance during reaching in patients with left visual neglect. Neuropsychologia, 42, 1107-1117.

McIntosh, R. D., Pritchard, C. L., Dijkerman, H. C., Milner, A. D., \& Roberts, R. C. (2002). Prehension and perception of size in left visual neglect. Behavioral Neurology, 13, 3-15.

Milner, A. D., Dijkerman, H. C., \& Carey, D. P. (1999). Visuospatial processing in a pure case of visual-form agnosia. In N. Burgess, K. J. Jeffery, \& J. O'Keefe (Eds.), The hippocampal and parietal foundations of spatial cognition (pp. 443-466). Oxford: Oxford University Press.

Milner, A. D. (1995). Cerebral correlates of visual awareness. Neurospychologia, 33, 1117-1130.

Milner, A. D., \& Goodale, M. A. (2006). The visual brain in action (2nd ed.). Oxford: Oxford University Press.

Milner, A. D., Dijkerman, H. C., McIntosh, R. D., Rossetti, Y., \& Pisella, L. (2003). Delayed reaching and grasping in patients with optic ataxia. Progress in Brain Research, $142,225-242$.

Milner, A. D., Dijkerman, H. C., Pisella, L., McIntosh, R. D., Tilikete, C., Vighetto, A., \& Rossetti, Y. (2001). Grasping the past. Delay can improve visuomotor performance. Current Biology, 11, 1896-1901.

Milner, A. D., Paulignan, Y., Dijkerman, H. C., Michel, F., \& Jeannerod, M. (1999). A paradoxical improvement of misreaching in optic ataxia: new evidence for two separate neural systems for visual localization. Proceedings of the Royal Society $B, 266,2225-2229$.

Mort, D. J., Malhotra, P., Mannan, S. K., Rorden, C., Pambakian, A., Kennard, C., \& Husain, M. (2003). The anatomy of visual neglect. Brain, 126, 1986-1997.

Perenin, M.-T. (1997). Optic ataxia and unilateral neglect: clinical evidence for dissociable spatial functions in posterior parietal cortex. In P. Their, \& H.-O. Karnath (Eds.), Parietal lobe contributions to orientation in $3 D$ space (pp. 289-307). Heidelberg: Springer-Verlag.

Perenin, M.-T., \& Vighetto, A. (1988). Optic ataxia: a specific disruption in visuomotor mechanisms. Brain, 111, 643-674.

Rice, N. J., Edwards, M. J., Schindler, I., Punt, T. D., McIntosh, R. D., Humphreys, G. W., Lestou, V., \& Milner, A. D. (2009). Delay abolishes the obstacle avoidance deficit in unilateral optic ataxia. Neuropsychologia, 47, 1553-1562.

Rorden, C., \& Brett, M. (2000). Stereotaxic display of brain lesions. Behavioural Neurology, 12, 191-200.

Rossetti, Y., \& Pisella, L. (2002). Several 'vision for action' systems: A guide to dissociating and integrating dorsal and ventral functions. In W. Prinz, \& B. Hommel (Eds.), Attention and Performance, XIX. Common mechanisms in perception and action (pp. 62-119). Oxford: Oxford University press.

Rossit, S., Malhotra, P., Muir, K., Duncan, G., Reeves, I., Birschel, P., \& Harvey, M. (2009a). The neural basis of visuomotor deficits in hemispatial neglect. Neuropsychologia, 47, 2149-2153.

Rossit, S., Malhotra, P., Muir, K., Reeves, I., Duncan, G., Livingstone, K., Jackson, H., Hogg, C., Castle, P., Learmonth, G., \& Harvey, M. (2009b). No neglect-specific deficits in reaching tasks. Cerebral Cortex, 19, 2616-2624.

Rossit, S., Muir, K., Reeves, I., Duncan, G., Birschel, P., \& Harvey, M. (2009c). Immediate and delayed reaching in hemispatial neglect. Neuropsychologia, 47 1563-1572.

Singhal, A., Kaufman, L., Valyear, K., \& Culham, J. C. (2006). fMRI reactivation of the human lateral occipital complex during delayed actions to remembered objects. Visual Cognition, 14, 122-125.

Westwood, D. A., \& Goodale, M. A. (2003). Perceptual illusion and the real-time control of action. Spatial Vision, 16, 243-254.

Wilson, B. A., Cockburn, J., \& Halligan, P. (1987). Behavioural inattention test. Titchfield: Thames Valley Test Company. 